\title{
Research on Innovation of Logistics Management Mode in E-commerce Environment
}

\author{
Jianwen Ye, Jianhua Zhang ${ }^{*}$, and Jia Ran \\ Management Engineering Department, Zhengzhou University, Henan Province, China \\ 1357568274@qq.com,969480705@qq.com
}

Keywords: E-commerce, Logistics management, Innovation

Abstract: In the promotion of e-commerce, the logistics industry gradually develops to the information and network direction, therefore, in the e-commerce environment, logistics management can not completely copy the management model under the traditional environment, However, the logistics management mode needs to be analyzed and adjusted again. This paper first describes the characteristics of logistics management mode under e-commerce, and then analyzes the shortcomings of logistics management mode in this environment, and finally puts forward the suggestion of management innovation mode.

\section{Introduction}

In today's society, the devlopment of e-commerce directly affects the operation of the logistics industry. In the e-commerce environment, the logistics market has both opportunities and threats. The traditional logistics management mode can not fully adapt to the current development situation, the threat factors gradually increase, many parts of the logistics industry also have defects, which hinder the effective development of e-commerce. Therefore, the experts in the electronic commerce field have discussed, and the discussion of the logistics management mode innovation under the e-commerce environment has become the main topic nowadays.

\section{The Characteristics of Logistics Management Mode in E-Commerce Environment}

The logistics management in E-commerce is built on the basis of the computer,It is the computer as the main means, all links closely linked. logistics management under E-commerce environment and traditional logistics management are very different, the traditional logistics management have many shortcomings, logistics management under E-commerce environment avoided the traditional drawbacks, combined with the further development of the computer. Logistics management under e-commerce requires relevant personnel to collect all kinds of information related to customers, to understand the different needs of different customers, through the analysis of customer demand to make a comprehensive decision(Haiyun Liu,2013). The logistics management in e-commerce environment has the following characteristics: 


\subsection{Informatization}

In the era of the Internet, information technology plays an important role, the information is the foundation, all the work is inseparable from the information. Under the environment of e-commerce, the logistics industry must establish a good information system, Through the information system can be timely and effective collection of different needs of different customers, and then the relevant personnel through the analysis of information to produce the corresponding goods, rather than produce something that no one needs.In addition, through the information system, customers, transportation companies, warehousing companies and other related links can understand the exact location of the goods, so that the relevant personnel can be prepared in advance (Deku Li,2013).

\subsection{Network}

Logistics management network is not only reflected in the storage and transmission of information, but also in the order, production and transportation of the entire logistics activities. The logistics management information system organically connects the external network with the internal network, enterprise and customer, and forms a complete network system (Aixiang Zhao, 2016).

\subsection{Multi-functional}

The traditional logistics enterprises only provide warehousing and transportation services, in the e-commerce environment, logistics enterprises not only provide warehousing and transportation services, and will provide door-to-door delivery and other demanding services, and even provide some of the different services requested by customers, thus making the logistics industry to go to a comprehensive development(Pian Guo,2016).

\subsection{Humanized}

The humanization of logistics management in the e-commerce environment is mainly reflected in the fact that it is based on collecting the different demand information of customers and then providing the corresponding services for these needs.

\subsection{Technology}

Modern logistics management is based on the basis of the computer, through the computer to collect information, and now with the development of the Internet, the computer towards the direction of more high-end technology development, therefore, e-commerce environment, logistics management presents a more scientific and technological characteristics.

\section{The Deficiency of Logistics Management Mode in E-commerce Environment}

\subsection{Logistics Enterprises Smaller}

At present, most of our logistics enterprises are small businesses, small businesses may not have sufficient funds to invest in the construction of a sound information management system, so that can not be timely and effective collection of customer needs, which can not provide services to meet people's needs. 


\subsection{The Lack of Complex Logistics Management Personnel}

Logistics is a complex type of industry, which makes a very high demand for personnel, and with these conditions of the management staff is very scarce. In addition, e-commerce is popular in the past two years, logistics management followed by e-commerce environment, and most of the logistics management talent is still accustomed to the traditional logistics management, can not be timely to adapt to e-commerce environment.According to the development of the logistics industry in China, Taojinghui and others have predicted the talents that China's logistics also needs from 2011 to 2025, as shown in Figure 1.

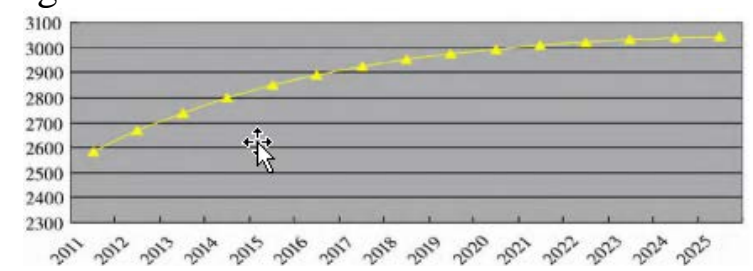

Figure 1 China's Logistics Talent Demand 2011-2025

It can be seen from Figure 1 that by 2025, China's demand for logistics talents has reached more than 30 million.

\subsection{People are Confined by Traditional Ideas, Can not Change Their Minds in a Timely Manner}

At present, with the rapid development of e-commerce, the domestic logistics industry has also been a good expansion, logistics management towards a more information and professional direction, but people are accustomed to the traditional environment of logistics management, the company's Employees may be old employees, have been accustomed to the previous work, for various reasons, they do not want to accept innovation, make a change in thinking, thus hindering the development of the logistics industry (Haner Zhao,2014).

\subsection{The Government's Support is not Enough}

At present, China's logistics market has not yet established a complete legal system and fair competition mechanism, therefore, accessing to the logistics market is very confusing, there is no a platform for fair competition, so unfair competition phenomenon is only increasing. The development of the logistics industry under the electricity business environment requires not only advanced machinery and equipment and ample funds to build a complete information management system, but also a good market environment and sound legal system and laws and regulations. Implementation and government support are closely related.

\subsection{Technical Equipment is Relatively Backward}

China is still part of the developing countries, compared with developed countries, whether in terms of management or technical equipment, China's logistics industry is still in a relatively backward position.The rise and development of the logistics industry is relatively late, the infrastructure is not perfect, so it can only guarantee a smooth flow of logistics activities, and can not complete the smooth progress of the entire logistics activities. In addition, each device can not meet the technical requirements, and thus can not guarantee the e-commerce environment, logistics management innovation work (Wentao Yuan,2017). 


\subsection{Logistics and Distribution System is not Perfect}

Now the logistics equipment of our country is not perfect, shortage of funds, old technology and equipment in the enterprise, still use the traditional way of information transmission and management methods, which can not accurately provide consumers with logistics information, so the logistics industry can not provide satisfied with the service, at the same time, the logistics industry can not be fully developed. In addition, China's logistics industry has not yet formed a unified standard, the development of enterprises are different, the market is very chaotic, hindering the development of the logistics industry in China, therefore, China's logistics industry is facing a very serious situation(Ka Zuo,2017).

\section{Innovative Suggestions on Logistics Management Mode in E-commerce Environment}

\subsection{To Expand the Scale of Enterprises, Learn from Foreign Logistics Enterprise Experience}

China's logistics industry is relatively backward, the infrastructure is relatively old-fashioned, the investment cycle is relatively long, so we should increase the way of capital integration of enterprises, then the government should support the first place, and then integrate foreign investment and market funds.Learning from foreign advanced logistics management innovation model, improving the logistics management system, optimize all aspects, so that China's logistics industry more perfect, more systematic logistics management, information technology, networking and so on.In this way, in the electricity business environment, the development of the logistics industry is more standardized and scientific, to speed up the development of China's logistics industry, to improve efficiency and increase efficiency. Shun Feng enterprises is the use of high-end technology and technology, combined with information technology, continue to invest funds to improve the company's technology and equipment, with the fastest efficiency for customers to mention services. Logistics enterprises should always adhere to the customer service for the purpose of improving service efficiency.

\subsection{To Strengthen the Training of Compound Talents}

Logistics industry is a complex type of industry, especially in the era of rapid development of e-commerce, the logistics business management personnel put forward higher requirements.Now is an information age, the development of logistics is also inseparable from the information technology, therefore, now the logistics management talent can not just follow the traditional management model, should understand the situation in the management of innovation, speed up the familiar and master computer technology, and be familiar with the information management system operating mode,understand the entire logistics operation process. Management of financial management, computer technology, data processing and international management theory training, to improve the staff's ideological and comprehensive quality (Hong Yang,2017).Fig. 2 is the training process of complex talents. 


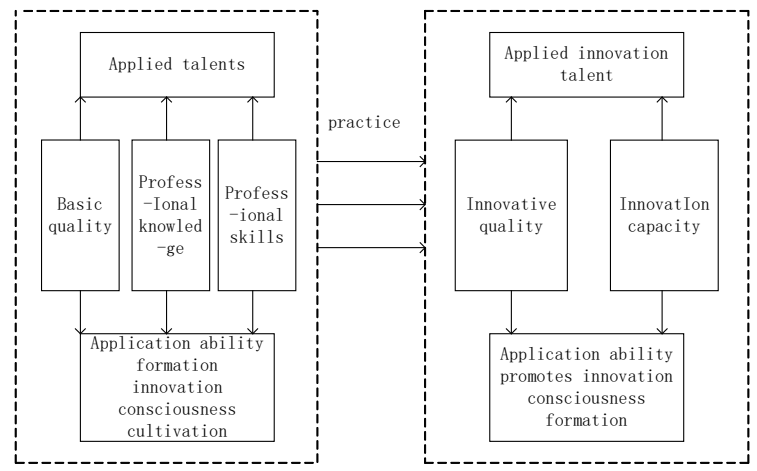

Figure 2 Composite talent training model

\subsection{The Liberation of Staff Thinking, Increase Innovation}

Most of the people in the logistics business are old employees who are accustomed to the way they work and the environment, they are reluctant to innovate because they feel that changes in work may disrupt their way of life and even endanger their work, They do not want to accept innovation. At this time, the company should regularly carry out ideological education, change the staff behind the ideological and cognitive, encourage them to innovate. In addition, you can carry out collective activities in the company to improve the enthusiasm of employees (Zhi Huang, 2016). Therefore, the innovative talent development model is shown in Figure 3.

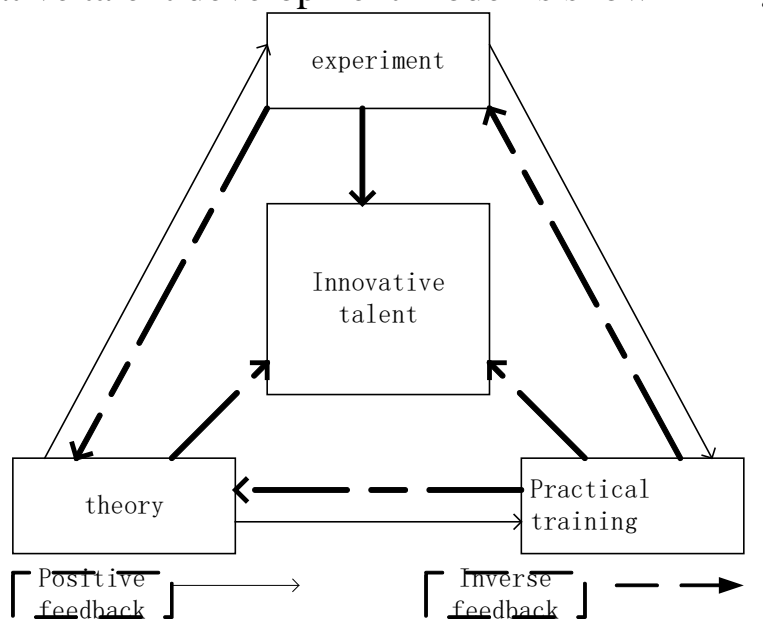

Figure 3 Innovative talent training model

\subsection{The Government to Increase Support for the Logistics Industry}

Nowadays, China's logistics market has not yet formed a complete set of legal systems, laws and regulations, and accessing to the logistics market is very chaotic, there is no legitimate competition in the market. Therefore, the government should improve the corresponding laws and regulations and related systems, regulate the logistics market to create an appropriate development environment. In addition, China's logistics enterprises are mostly small businesses, enterprises sometimes there will be insufficient funds, at that time the government should support efforts to provide enterprises with sufficient funds to improve the infrastructure and to build a complete set of information management system. 


\subsection{Improve the Logistics and Distribution System}

Nowadays, logistics and distribution mainly rely on network information technology, and combine with advanced software technology to carry out. Although the distribution process with the help of network technology and customer demand for the scientific delivery of goods, because of the current logistics enterprises within the mechanism is not perfect, which can not meet the desired requirements. Therefore, the logistics industry should be sufficient funds to improve the information systems and technical equipment, the establishment of a sound logistics and distribution system(Yuan Wang,2016).At the same time, the joint distribution model is adopted to achieve cross-regional cooperation in commodity distribution. At present, the joint distribution mode mainly uses collaborative joint distribution (Figure 4) and cohesive joint distribution (Figure 5).

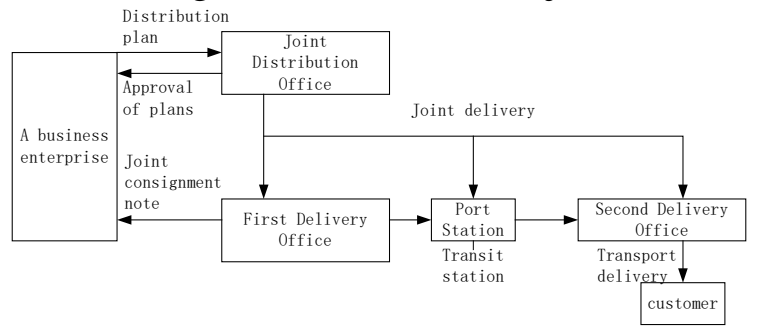

Figure 4 Collaborative joint distribution

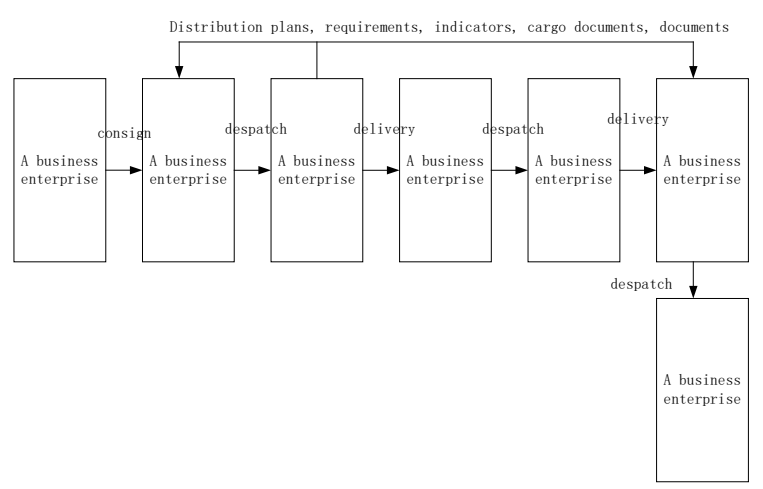

Figure 5 Joint delivery

\section{Conclusions}

Our country logistics start relatively backward, the technical equipment is relatively old fashioned, therefore, the domestic logistics management needs to innovate, draw lessons from the foreign management experience, introduce the advanced foreign technology, at the same time, the government also needs to strengthen the support, promote the domestic logistics industry development, improve the domestic logistics competition ability, and make contribution to our country's economic development.

\section{Acknowledgements}

This work is supported by the Excellent Young Teacher Development Fund Project of Zhengzhou University (Foundation No.2015 SKYQ15) and the Innovation and Development Fund of Zhengzhou University School of Management Engineering (Foundation No. 20170604). 


\section{References}

[1] Aixiang, Zhao, 2016. Electronic commerce environment logistics management innovation development path research, Reform and strategy. 32 (12), 67-70.

[2] Deku, Li, 2013. E-commerce environment under the logistics management innovation, National circulation economy. 27 (08), 39-43.

[3] Haner, Zhao, 2014. E-commerce environment under the logistics management innovation research, Journal of Suzhou Education College. 17 (05), 8-9.

[4] Hong, Yang, 2017. E-commerce environment under the logistics management innovation, Private technology. (04), 95.

[5] Haiyun, Liu, 2013. On the logistics management innovation in e-commerce, China Business. (24), 91-92.

[6] Jia, Zuo, 2017. Explore the logistics management innovation under the e-commerce environment, Chinese Business Theory. (12), 23-24.

[7] Pian, Guo, 2016. E-commerce background of the logistics management innovation strategy research, China Business Theory. (33), 25-26.

[8] Wentao, Yuan, 2017. E-commerce environment under the logistics management innovation, Logistics Engineering and Management. 39 (04), 55-56.

[9] Yuan, Wang, 2016. Analysis of e-commerce environment under the logistics management innovation, China Business Theory. (20), 82-83.

[10] Zhi, Huang, 2016. E-commerce environment, enterprise logistics management innovation analysis, Enterprise reform and management. (24), 10-11. 